\title{
FAMILIAL HOMOZYGOUS HYPERCHOLESTEROLAEMIA- A CASE REPORT
}

\author{
Shailaja Potdar ${ }^{1}$, Jayesh Panot ${ }^{2}$, Vandana Kumavat ${ }^{3}$, Sunil Junagade
}

${ }_{1}^{1}$ Associate Professor, Department of Paediatrics, Rajiv Gandhi Medical College, Thane. ${ }^{2}$ Assistant Professor, Department of Paediatrics, Rajiv Gandhi Medical College, Thane. 3 Professor and HOD, Department of Paediatrics, Rajiv Gandhi Medical College, Thane. ${ }^{4}$ Associate Professor, Department of Paediatrics, Rajiv Gandhi Medical College, Thane.

\section{ABSTRACT}

\section{BACKGROUND}

Familial Hypercholesterolaemia (FH) is a monogenetic autosomal codominant disorder caused by mutation affecting the LDL receptors. It is characterised by elevated LDL cholesterol, xanthomas and early Coronary Artery Disease (CAD). Homozygous Familial Hypercholesterolaemia (HoFH) is of a rare occurrence. Management of HoFH patients requires lifestyle modifications and medical therapy. Untreated homozygous patients rarely survive to adulthood. We report an 8 years old male child who presented with multiple xanthomas over skin since 9 months and had deranged lipid profile consistent with Homozygous FH. On further evaluation, whole family had deranged lipid profile fulfilling criteria of familial hypercholesterolaemia.

\section{KEYWORDS}

Hypercholesterolaemia, Homozygous, Xanthomas.

HOW TO CITE THIS ARTICLE: Potdar S, Panot J, Kumavat V, et al. Familial homozygous hypercholesterolaemia- a case report. J. Evolution Med. Dent. Sci. 2017;6(18):1461-1463, DOI: 10.14260/Jemds/2017/319

\section{BACKGROUND}

Familial Hypercholesterolaemia (FH) is a genetic disease that presents with high levels of serum Low Density Lipoprotein (LDL), xanthomas and early Coronary Artery Disease (CAD). ${ }^{1}$ Familial hypercholesterolaemia is an autosomal codominant disorder characterised by a gene dose effect, in that the individuals with two mutant LDL receptor alleles (FH Homozygous) are more affected than those with one mutant allele (FH Heterozygous). FH in Heterozygous state is more common and occurs with a prevalence of approximately 1 in 500 worldwide, making it one of the most common single gene disorders, whereas FH in Homozygous state is rare and occurs in approximately 1 in million persons. Familial hypercholesterolaemia was the first genetic disorder recognised to cause Myocardial Infarction (MI).2,3 These patients are at a high risk of developing CAD and sudden death, unless the condition is recognised and treated promptly.2,4 Here, we report an interesting case of homozygous FH for its rarity in the prevalence rate and for academic interest.

\section{Case Report}

An 8-year-old male child presented with the complaints of multiple yellowish lesions over various parts of body since 9 months. Child was apparently well till 7 years, when his mother noticed yellowish lesions on elbows, knees and buttocks. Lesions gradually increased in number and size. There was no history of consanguinity, family history of acute myocardial infarction, stroke, dyslipidaemia or xanthomas.

Financial or Other, Competing Interest: None.

Submission 18-01-2017, Peer Review 15-02-2017,

Acceptance 21-02-2017, Published 02-03-2017.

Corresponding Author:

Dr. Jayesh Panot,

Assistant Professor,

Department of Paediatrics,

Rajiv Gandhi Medical College,

Thane.

E-mail: jayeshpanot@gmail.com

DOI: $10.14260 /$ jemds $/ 2017 / 319$
The patient was born to non-consanguineous parents and his developmental milestones were normal. There was no history of chest pain, breathlessness, hypertension, diabetes mellitus or hypothyroidism. Physical examination of the child showed tuberous xanthomas on the knees and elbows and in the gluteal region.

On investigations, plasma lipid levels of the child were Total Cholesterol (TC) $640 \mathrm{mg} / \mathrm{dL}$; low density lipoproteins (LDL) $556.2 \mathrm{mg} / \mathrm{dL}$, Triglycerides (TG) $299 \mathrm{mg} / \mathrm{dL}$ and High Density Lipoprotein (HDL) $24 \mathrm{mg} / \mathrm{dL}$. Echocardiography was normal. Liver enzymes, renal functions, blood glucose and uric acid was normal. Plasma cholesterol levels of child's parents and siblings were also raised in $\mathrm{mg} / \mathrm{mL}$ as fathers 397 , mother 395, elder sister 355, younger sister 301, young brothers 290 and 147.

There was no history of cardiac problem in the family. The diagnosis of $\mathrm{HoFH}$ was based on the clinical characteristics, very high LDL level of the patient (640 $\mathrm{mg} / \mathrm{dL}$ ) and all family members who had high cholesterol levels, early age of onset. The biopsy of skin was consistent with tuberous xanthoma. Child was started on Atorvastatin $30 \mathrm{mg} /$ day and was gradually increased to $80 \mathrm{mg} /$ day in view of poor response. Patient was advised diet and lifestyle modification. Child is following up with us with no new lesions and no new complaints till now.

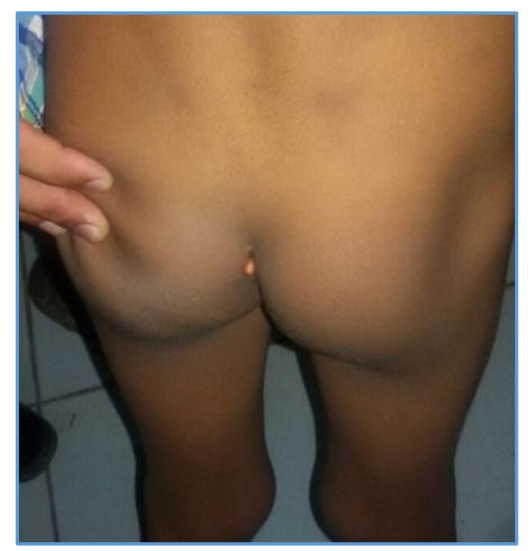

Figure 1. Image showing Xanthoma on Sacral Region 


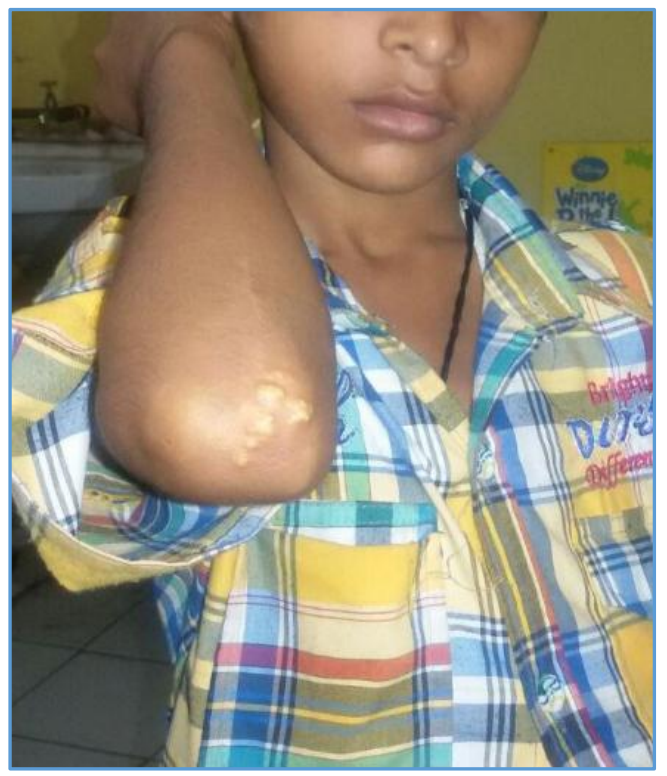

Figure 2. Image showing Xanthoma on Right Elbow

\section{DISCUSSION}

Simon Broome formed criteria for definite and possible diagnosis of FH.

Definite Familial Hypercholesterolaemia is defined as -

1. Cholesterol > $6.7 \mathrm{mmol} / \mathrm{L}[260 \mathrm{mg} / \mathrm{dL}]$ or $\mathrm{LDL}$ cholesterol $>4 \mathrm{mmol} / \mathrm{L}[155 \mathrm{mg} / \mathrm{dL}]$ in a child $<16$ years or total cholesterol concentrations $>7.5 \mathrm{mmol} / \mathrm{L}$ $[290 \mathrm{mg} / \mathrm{dL}]$ or LDL cholesterol $>4.9 \mathrm{mmol} / \mathrm{L}[190$ $\mathrm{mg} / \mathrm{dL}]$ in an adult, PLUS

2. Tendon xanthoma in the patient or evidence of these signs in first- or second-degree relative, OR

3. DNA-based evidence of an LDL-receptor mutation, familial defective apo B-100 or a PCSK9 mutation.

Possible Familial Hypercholesterolaemia is defined as -

4. Criteria 1 plus 1 of 5 or 6 .

5. Family history of myocardial infarction: Below age of 50 in second-degree relative or below age of 60 in firstdegree relative.

6. Family history of raised cholesterols - > $7.5 \mathrm{mmol} / \mathrm{L}[290$ $\mathrm{mg} / \mathrm{dL}]$ in adult $1^{\text {st }}$ or $2^{\text {nd }}$ degree relative or $>6.7$ $\mathrm{mmol} / \mathrm{L}$ [260 mg/dL] in child or sibling under 16.5

The Diagnosis of Homozygous FH in our Patient was based on the Presence of -

1. Serum cholesterol levels $[640 \mathrm{mg} / \mathrm{dL}(16.6 \mathrm{mmol} / \mathrm{dL})]$ with normal triglyceride levels.

2. Appearance of xanthomas in the first decade of life.

3. Documentation of hypercholesterolaemia in both parents and in all of the siblings.

Due to technical constraints LDL receptor studies and genetic analysis could not be done in our patient.

Management of $\mathrm{FH}$ patients, especially homozygous is challenging. Beyond genetic counselling for patients and the families of the patients diagnosed with $\mathrm{FH}$, treatment options involve decreasing serum cholesterol levels and increasing cholesterol removal. ${ }^{6}$ Therapies available include diet and lifestyle modifications focusing on a reduced-cholesterol diet, pharmacologic treatment affecting cholesterol absorption and metabolism, and LDL apheresis to remove LDL from the serum to decrease the levels.

\section{Diet and Lifestyle}

FH usually responds poorly to the low lipid diet.

\section{The Diet should consist of}

- Total fat intake is $30 \%$ or less.

- Saturated fats are $10 \%$ or less.

- Intake of dietary cholesterol less than $300 \mathrm{mg} /$ day.

- Saturated fats are replaced by increasing the intake of monounsaturated and polyunsaturated fats.

Primary hypercholesterolaemia occurs as a monogenic defect in lipoprotein catabolism by a mutation in the LDL receptor gene. The rate at which the LDL is removed from the plasma is determined by the heterozygous or homozygous state of the individual. Triglycerides are normal to mildly elevated and HDL may be slightly decreased. Receptor negative patients have $<2 \%$ normal LDL receptor activity, whereas those who are receptor defective may have as much as $25 \%$ normal activity and a better prognosis. LDL cholesterol is removed from plasma in the heterozygous state at $2 / 3^{\text {rd }}$ of the normal rate resulting in 2 to 3 fold elevation of LDL cholesterol, whereas in the homozygous state it is removed at $1 / 3^{\text {rd }}$ of the normal rate resulting in 6 to 8 fold elevation of plasma LDL.

Clinically homozygous children usually present with cutaneous xanthomas during early childhood and cardiovascular abnormalities in the second or third decade of life as happened with our patient who had almost all of these features except the CVS abnormalities, which usually manifest in second decade. ${ }^{7}$ Similar instances of homozygous FH have also been reported by others also. Family history is informative, because premature heart disease is strongly prevalent among relatives of both parents.

The management of FH patients, especially homozygotes has been a challenging job. Besides dietary control, a number of therapies have been advocated and early Institution of such therapy may increase the long-term survival rates. HMG COA reductase inhibitors known as statins are remarkably effective in lowering the LDL cholesterol levels. ${ }^{8}$ Combination therapy with ezetimibe, selectively blocking cholesterol absorption in the gut results in further modest decline in LDL levels. It has largely replaced the bile acid sequestrants. Other cholesterol lowering medications like nicotinic acid and fibrates have less often been used in children.9,10 The NCEP expert panel for children and adolescents recommends that consideration may be given to pharmacologic treatment of hyperlipidaemia if the child is at least 10 years old and the adequate period of dietary restriction at least 6 months has not achieved therapeutic goals. The guidelines further specify that in rare cases an individual may begin therapy earlier when there is an extremely high level of cholesterol and family history of early coronary disease is prevalent. Considering the above fact, we have put our patient on atorvastatin $80 \mathrm{mg}$ once a day, besides dietary control LDL- 
apheresis has proven its clinical utility in patients who cannot be adequately treated by diet and drug therapy alone.

Liver transplantation if considered should be done prior to the development of severe coronary artery disease. Followup of the patient will make clear the effect of the above-mentioned therapy in lowering the serum levels of LDL cholesterol reducing the size of xanthomas and also in preventing the complications such as coronary artery disease and premature death.

\section{CONCLUSION}

Familial hypercholesterolaemia is a serious disorder, untreated homozygous patient rarely survive till adulthood. Sudden death due to cardiac complication is known. Though early diagnosis, monitoring, treatment and lifestyle modification will give us a favourable outcome. The available treatments of LDL apheresis can slower the progression of atherosclerosis and liver transplantation is also successful in decreasing LDL cholesterol level improving the outcome. Effective screening on suspicion and timely treatment will help to improve the complication and outcome.

\section{REFERENCES}

[1] Khurana VK, Mehta RK, Chandra K. Homozygous familial hypercholesterolemia: case report and Review of literature. Am J Intern Med 2014;2(2):34-40.

[2] Neal WA. Disorders of lipoprotein metabolism and transport. In: Kliegman RM, Stanton BF. eds. Nelson Textbook of Pediatrics. 19th edn. Vol. 1. Philadelphia: Saunders 2011:470-82.
[3] Jayaram S, Meera S, Kadi S, et al. An interesting case of familial homozygous hypercholesterolemia. A brief review. Indian J Clin Biochem 2012;27(3):309-13.

[4] Parihar RK, Razaq M, Saini G. Homozygous familial hypercholesterolemia. Indian J Endocrinol Metab 2012;16(4):643-5.

[5] Varghese MJ. Familial hypercholesterolemia: a review. Ann Pediatr Cardiol 2014;7(2):107-17.

[6] Wiegman A, Gidding SS, Watts GF, et al. Familial hypercholesterolaemia in children and adolescents: gaining decades of life by optimizing detection and treatment. Eur Heart J 2015;36(36):2425-37.

[7] Gupta M, Sharma RB, Parakh M. Pseudo-homozygous type Ila hypercholesterolemia. Indian Pediatr 1997;34(8):734-7.

[8] Eiland LS, Luttrell PK. Use of statins for dyslipidemia in the pediatric population. J Pediatr Pharmacol Ther 2010;15(3):160-72.

[9] Daniels SR, Greer FR, Committee on Nutrition. Lipid screening and cardiovascular health in childhood. Pediatrics 2008;122(1):198-208.

[10] Klose G, Laufs U, März W, et al. Familial Hypercholesterolemia: developments in diagnosis and treatment. Deutsches Ärzteblatt International 2014;111(31-32):523-9. 